\title{
Is it time for another medical curriculum revolution?
}

M any physicians would agree that medical school was long and arduous, featuring some courses that ultimately proved of dubious relevance to their current practices. That might not be as true for younger physicians who trained during the time of widespread adoption of problem-based learning. In this issue (page 34), CMAJ publishes a systematic evaluation of problem-based learning, which suggests that it improves critical thinking and skills in the social dimensions of medicine, long after graduation. ${ }^{1}$

Beyond problem-based learning, we wonder why no one seems to pay attention to another potential revolution in medical education, a 3-year curriculum. In Canada, we have an ongoing 30-year natural experiment, where 2 Canadian universities, namely, McMaster University and the University of Calgary, opted for a 3-year curriculum while all other medical schools retained the customary 4 years of training. In contrast to many US schools, Canadas's two 3-year schools have not condensed 4 years of classes into 3 by teaching on Saturday and across the summer.

Is this extra year necessary? Training each medical student in Canada is costly both in time and money. Each student requires hundreds of hours of time from established family physicians, specialists and medical educators - time that otherwise could be spent caring for patients. In terms of raw financial cost, a conservative estimate of cost to Canadian taxpayers for the extra year of education is about $\$ 170$ ooo per student. ${ }^{2}$ The extra year also represents a substantial financial burden for students, with annual tuitions ranging from \$2I8I at Université Laval to \$16 862 at the University of Toronto.

Based on circumstantial rather than comparative evidence, physicians trained in 3-year programs do not appear to be any less competent than graduates of 4 -year programs. Licensing authorities have not signalled any concerns about inferior test scores, at least not publicly. Family medicine and specialty training programs have not identified deficiencies in graduates of 3-year programs. Nor has the Canadian Medical Protective Association indicated that such physicians are at increased risk of being the subject of complaint.

No longer a single, undifferentiated profession, modern medicine is a collection of specialties, including the first-contact specialties of family and general practice. Specialists whose expertise ought to be narrow but deep should have limited exposure to general medical theory and practice and then focus primarily on learning their specialties. Front-line practitioners, on the other hand, need major exposure to the tools that will equip them to diagnose and manage the broad range of health problems that presents ${ }^{3}$ and should spend much less time on the finer points of dealing with advanced and complex diseases. ${ }^{4}$

Core competencies can be defined as the essential knowledge and skills required of all medical practitioners in order to think, talk and act like a doctor. Every physician needs to be able to make a correct diagnosis, an essential first step to the next one: treatment and prognosis. ${ }^{5}$ Thereafter, it is the physician's duty to teach the patient about the illness and its probable course. Core training should also ensure that all physicians are able to perform critical appraisals of medical literature, to communicate with their patients and other health professionals, to understand the ethics of their profession and to understand basic public health principles. How long should that take?

Are 4 years vital, particularly when graduation from medical school is but the first step on a much longer journey that requires a minimum of 2 additional years for family practice licensure and 5 additional years for specialists?

No one has any hard evidence in response.

Cutting I year would reduce training costs and costs to universities and taxpayers. Physicians would add I year to a lifetime of practice, which would help resolve Canada's physician shortage. Furthermore, this year would accrue at a time of peak intellectual and physical ability for the physician.

With so much at stake, studies should be undertaken to compare short-term outcomes, particularly medical licensing examination scores, among graduates of 3-year and 4-year curricula. Long-term outcomes, such as the proportion of graduates in leadership roles, the proportion serving areas of greatest need and the proportion of physicians subject to licence restrictions or disciplinary actions, should also be studied.

Only with more evidence can we accurately gauge whether the current commitment to a 4-year curriculum is justified. Without systematic evaluations, deans of medicine will be left with only tradition as a defence when education ministers demand better evidence, given the high professional and social costs. As for medical students, they should ask whether a fourth year will make them better and wiser physicians rather than simply older and poorer ones.

Kenneth M. Flegel MDCM MSc

Senior Associate Editor, $C M A J$

Paul C. Hébert MD MHSc

Editor-in-Chief, CMAJ

Noni MacDonald MD MSc

Section Editor, Public Health, CMAJ

With the Editorial-Writing Team (Matthew B. Stanbrook MD PhD, Barbara Sibbald BJ and Amir Attaran LLB DPhil)

\section{REFERENCES}

I. Koh GCH, Khoo HE, Wong ML, et al. The effects of problem-based learning during medical school on physician competency: a systematic review. $C M A J$ 2008;178:34-4I.

2. Valber LS, Gonyea MA, Sinclair DG, et al. Planning the future academic medical centre: conceptual framework and financial design. Ottawa: Canadian Medical Association; 1994.

3. Miettinen OS, Flegel KM. Medical curriculum and licensing: still in need of radical revision. Lancet I992;340:956-7.

4. Flegel KM, Palepu A. Training on the internal medicine teaching wards. CMAJ 2003;168:997-8.

5. Miettinen OS, Flegel KM. Elementary concepts of medicine: VIII. Knowing about a client's health: gnosis. J Eval Clin Pract 2003;9:333-5. 